\title{
Aerodynamics of an aerofoil in transonic ground effect: numerical study at full-scale Reynolds numbers
}

G. Doig

Q.coig@unsw.edk.zu

School of Mechanical and Manufacturing Engineering

The University of New South Wales

Sydney, Australia

\section{A. J. Neely}

School of Aerospace, Civil and Mechanical Engineering

The Unversity of New South Wales at the Australian Defence Force Academy

Canberra, Australia

\section{D. Myre}

Aerospace Engineering Deparment

The United States Naval Academy

Maryland, USA

\section{ABSTRACT}

The potential positive effects of ground proximity on the aerodynamic pertomance of a wing or terofoil have long been established, but at transonic speeds the formation of shock waves between the body and the ground plane would bave significant consequences. A numerical study of the aerodynamics of an RAE2822 acrofoil section in ground effect hight was conducted at freestroan Mach numbers from 0.5 to 09 , at a range of ground clearances and angles of incidence. It was found that in general the aerofoil's lifing capability was still improved with decreasing ground clearanes ap until the point at which a lower surface shock wave formed (most commonly at the lowest clearances). The critical Mach number for the section was reached considerably sarlior in ground effect than it would be in freestream, and the buffet boundary was therefore also reached at an earher stage. The flownelds observed were relatively sensitive to changes in any given variable, and the lower surface shock had a destabilising effect on the pitching characteristics of the wing, indicating that sudden changes in both altivde and atitude would be experienced during sustained transonic thight close to the grownd plane. Sinee grownd proximity hastens the lower suface shock formation, no gain in aerodynamic efficiency can be gained by tying in ground effect one that shock is present. 


\section{NOMENCLATURE}

a angle of incidence

c chord

$C_{l} \quad$ coefficient of hit

$C_{D} \quad$ co-eficient of drag

$C_{f} \quad c o-e f f c i e n t$ of skin friction

$C_{p}$ co-efficient of pressure

b drag force

h minman height above ground plane

L. negative lift force (downfore)

M local Mach number

$M_{\infty} \quad$ freesteam Mach mmber

$V_{\text {in }} \quad$ freestream velocity

$x \quad$ distance from leading edge

\subsection{INTRODUCTION}

Traditionally, aeronatical ground effect researoh (excluding study of vertical take-ofr and landing (VTOL) bas concentrated on the properties of wings in incompressible lows at relatively low stbsonic Mach mubers. Applications have included aircrat in landing or takeof modes or aircraft designed specifically to fly in ground effect (Wing-in-ground-effect, or WlG vebicles). In these cases, proximity to the gromd serves to enbance the lifing performance of the wing, and often the aerodynamic efficiency (ift/drag, $L / D)$ as well ${ }^{(1-3)}$. The principal sffect of the ground is to move the stagnation point downwards as the wing experiences a reduction in velocity and an increase in pressure on the lower surface, accompanied by an increase in local velociry at the wpper surface

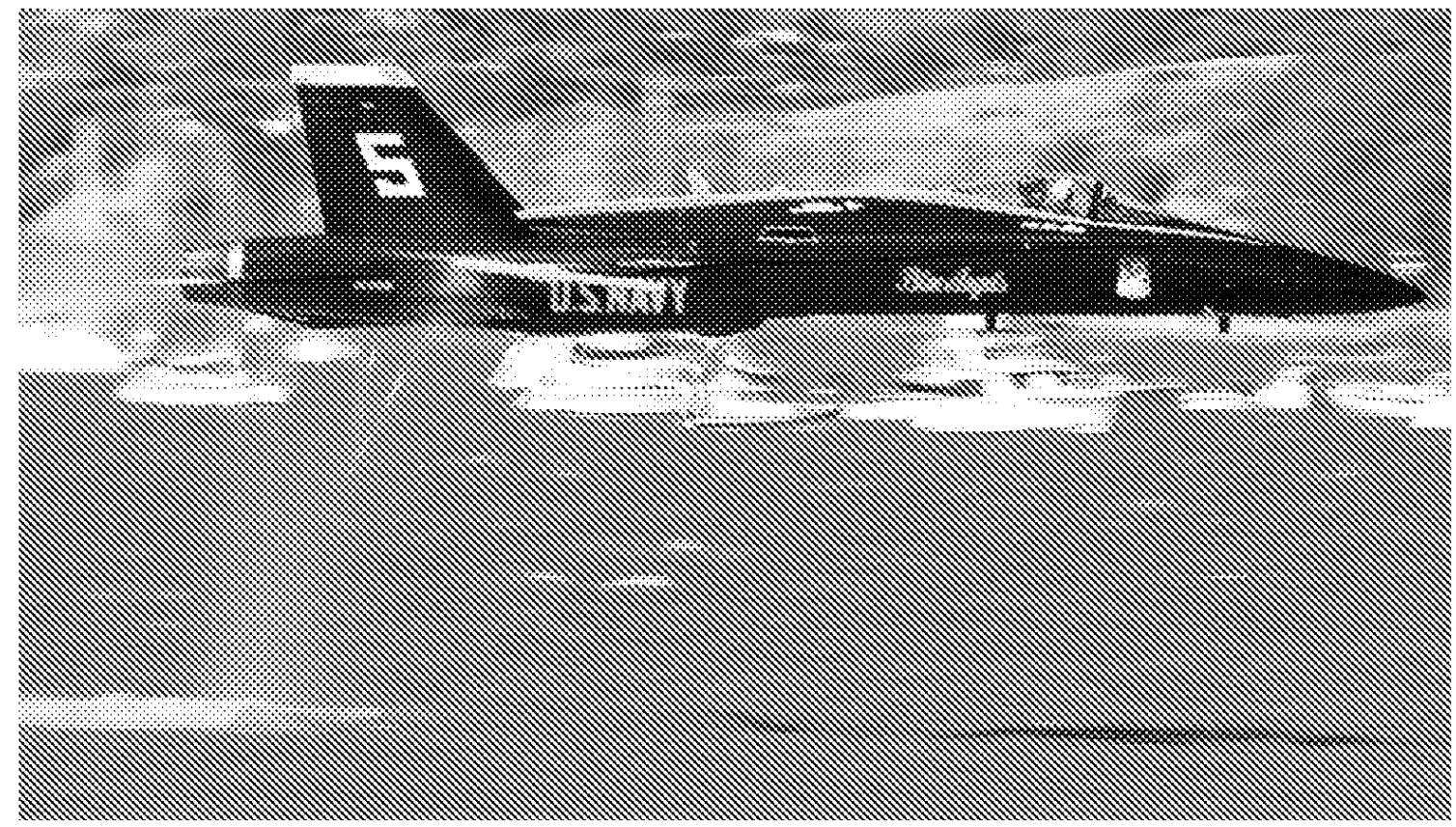

Figure 1. A US Nayy Blue Angel demonstration aircraft during a Mach 0.95 pass, highlighting shock/surface interaction with permission: Mat: Nissnn. 
suction peak near the leading edge $e^{(1,2)}$. This increases the effective angle of attach of the wing and lift as a consequence. Depending on the geometry, the gromb effect can have a relatively small effect on drag. Therefore, the overall efficiency (L/D) of the wing can be greatly improved as ground clearance is decreased.

A much-improved understanding of the aerodynamic infwence of compressible ground effects and of shock/ground interaction is timely, particularly given recuring interest in high-speed subsonic (freestream Mach number, $M_{\infty}=04$ ) WlG arcraf ${ }^{(3)}$, as well as magnetic-Levitation space vebicle launch systems ${ }^{(t)}$, and high sped ail vehicles increasingly pushing towards the midsubsonic Mach number range . An example of shock/ground (in this case, water) interaction is shown in Fig. 1, where a US Navy Bhe Angel pertoms an sxtremely low-lovel pass in San Francisco and generates a series of shockwaves, some of which influence the water surtace.

In an extensive review of WG aircraft aerodynamics and techology, Rozhdestrensky affmos 'it can be stated that lithe is still lnown with regard to GE (ground effect) at high sabsonic Mach mubers' ${ }^{\prime \prime}$. Brief test studies indicate that increased aerodynamic efficioncy may be possible for a high aspect ratio wing in grown effect at high subsone Mach numbers ${ }^{7}$, but some simple analytical treatments suggest the opposito's. However, the effect of the fomation of shock waves either on the wing upper surface, or berween the wing and the ground, bas not been considered in detai\}.

Other andytical studies using boundary dement methods which considered subsonic and supersonic compressible fow over aerofols in ground effect were limited by formulations can only be generally applied to thin aerofoils ${ }^{(2,9)}$. Despite this, resuls were presented for a (relatively thick) NACA 4412 aerofoll at $0^{\circ}$ incidence, indicating that for a freestream Mach number of 0.5 , the compressible case predicts $C_{L}$ as being $12 \%$ bigher for grownd deanances greater than a beightto-chord ratio (h/c) of 0.5 , below which the compressible $C_{L}$ increasingly agrees with the incompressble prediction. No discussion was offered as to why this occurs and the nothod does not facilitate a detailed examination of the flowfield.

The present study applies RANS modelling to the sination of a two-dimensional aerofol in ground effect at Mach numbers from 0.5 up to 0.9 . The inchision of a comprehensive set of experimental results for wings and aerofons in transonic nowfields in the Advisory Gromp for Acronautical Research and Development (AGARD) report of the late 1970 s which was specifically compled to provide numerical researchers with a validation databe ${ }^{(0)}$, bas led the RAE2822 to become a conmon benchmark for transonic asrodynanic simulations. The decision was made to make use of this gemety not just becanse of the obvious possibilty for validation of the bumerical nethods employed, but in order to enable the recontextualisation of this wellknown aerofol, such that its changed characteristics when in ground effect would stand in contrast to their 'freeflight' traits famliar to any researcher who has undertaken transonic acrofoil cole validation. The present study inchded angle of incidence, Mach number (and by inferetuce Reynolds number) and gromd clearance as variables. Atbough the shape and camber of the body are clearly also importan variables, ading these infuences would have resulted in a probibitive amount of data. Relevant parameters for the aerotoll in ground proximity are shown in Fig. 2.

\subsection{NUMERICAL METHOD}

The mumerical method applied to produce all results in this section is very similar to that described in detail the accompanyog part to this papes, "Methods for blowdown wibd-tumel scale testing (11), only differing in that in this instance it was appled to a purely two-dimensional geometry In order to ensure the method established for conducting thee-dimensional bmerical analysis of the US Naval Academy wind-unnel experments was also suffienty applicable to 


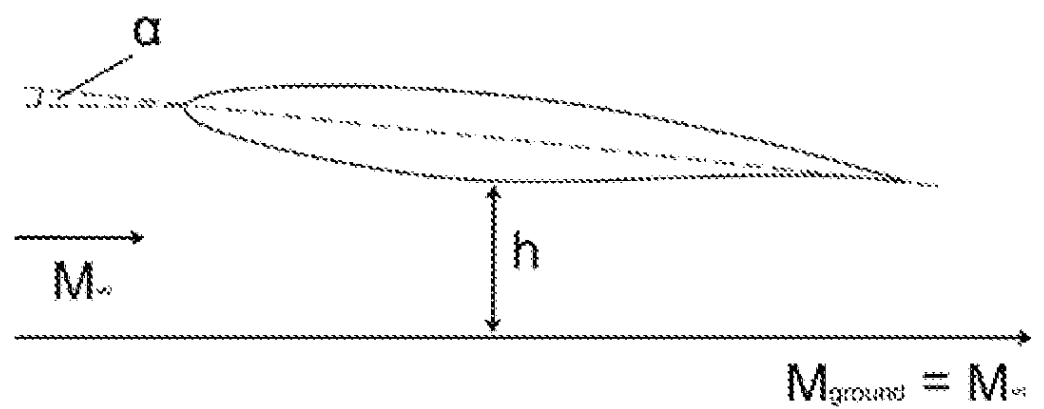

Figure 2. Parameters for an aerofoll in ground effect.

the present cases, additiond validation was andertaken using the wo-dimensional RAE2822 with reference to the AOARD report previously mentioned ${ }^{10}$.

A commerual finte-volume Reynolds-Averaged Navier Stokes code, Fuent $63^{(12)}$, was used to generate the results. A pressure-based, coupled solver was applied to obtain flow solutions, and convergence criteria were deemed to be met not only when the mass and momentum scaled-residual errors ceased to change by more than approximately $0.01 \%$ over 1,000 continued itcrations, but also when the aerodynamic forces on the body ceased to change by more than $0.01 \%$ over 1,000 further iterations (for the steady-state simulations). All cases were run in 64-bit double procision using a second order node-based upwind discretisation scheme, and a standard thee-coeficient Sutherland viscosity nodel was appled ${ }^{(3)}$, The choice of the pressure-based solver over the avaliable density-based solver is discussed at the end of this section.

\subsection{AGARD 'Case 9 ' comparisons}

The AGARB 'Case 9' (a frestream Mach mmber of 0.73 and a corrected angle of incidence of $2.79^{\circ}(10)$ involves a strong nomnal shock wave sitting on the upper surface at approximately $x / c=0.53$. The boundary layer behind the shock does not separate, allowing the flowfeld to be effectively treated as stable and steady-state. The report indicates that a transition trip was located at $x / 0=0.03$, and the turbulent intensity of the oncoming thow was determined to be $0.1 \%$. Both of these features were reproduced in the comparison simulations. The RAE 2822 section, at an aspect ratio of three and chord of $0.61 \mathrm{~m}$ (nn conditions yiclding a Reynolds number of approximately $6.5 \times 10^{6}$ ), was designed to provide two-dimensional fow at the semi-span. It bas since been sbown that this aspect ratio is bot necessarily sufficient to ensure twodimensional flow ${ }^{(t+15)}$, and the results were infuenced by the tunnel wals. Slotted walls were used to treat the boundary layers there; not only is litte detal given about this in the original report but this presents a scenario difficalt to replicate in CFD,

Due to the wall infuenee, flow conditons for two-dimensional simulations are rominely corected, sometines by fixing the solution values for $C_{2}$ and leting the solution find its own frestrean conditions, or by adusting either the Mach number or angle of incidence mamaly to match the experimental pressure distribution. The hater approach has been ascu here based on the suggestions of cook $a f^{(10)}$. The value of a used, $2.79^{\circ}$, is consiuerably altered from the experimental value of $319^{\circ}$. As is common practice, the tumel walls are not considered, and the aerofoil is therefore treated as existing in fres, unbounded flight. 


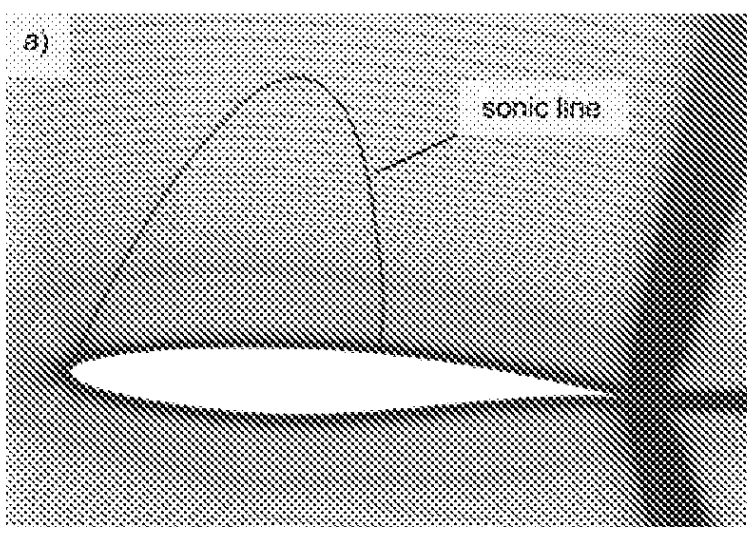

(a)

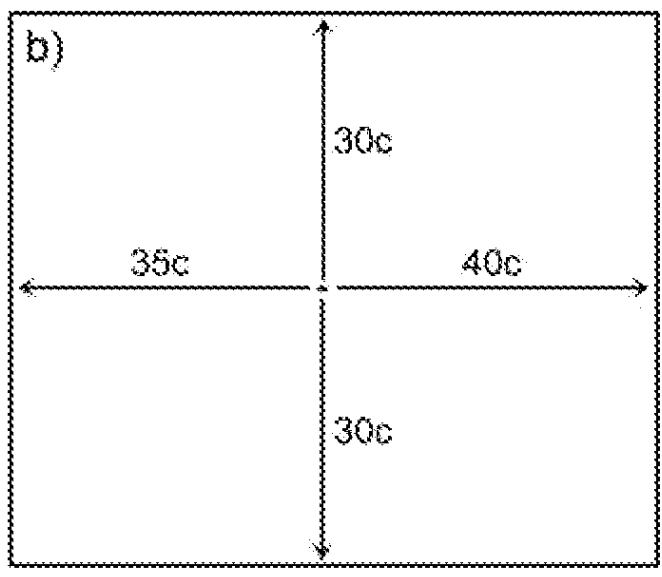

(b)

Figure 3 Sample mesh (a) and comain extent (b) for RAE 2822 'Case 9 ' simulations

\subsection{Mesh and boundary considerations}

The results presented in this section were generated by the Spalat-Allmaras tubulence nodel, the choice of which is dischssed in the following section. All meshes were structured muti-block grids, the general layout of which can be seen in Fig. 3(a). The appropriate location for the farfeld boundaries was examined simply by comparing the resuls from one simulation with boundaries as shown in Fig, 3(b), to those with an addition ten chord length in the domain in all directions. The imfuence of the boundaries on the solution when placed this far from the wings proved to be negligible, resulting in a changed prediction of the aerodynamic coefficients of less than $001 \%$

To ensure a mesh-independent solution, coarse, standard and fue meshes were constmoted for evaluation. Local hanging-node refinement of the mesh at the shock location was also performed on the standard mesh. The coasse mesh contained 320 nodes on the wing surface and a total of 130,000 cells. The standard mesh contained 256,000 cells with 545 nodes on the wing. The fne mesb was simply the standard mesb with each cell quartered, and thus contained a hithe over 1 millon cels. The inital comparison to the experimenal pressure distribution, presented in Fig, 4, shows excellent agreement for all mesbes. The shock location is well-predicted, at

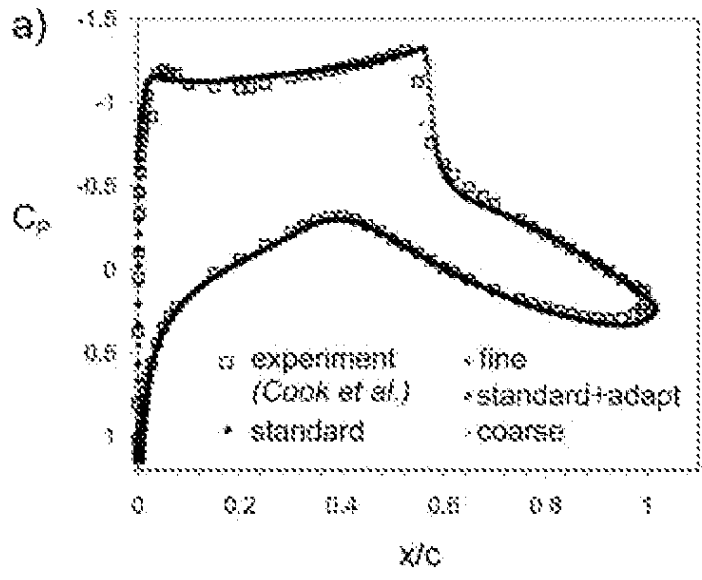

(a)

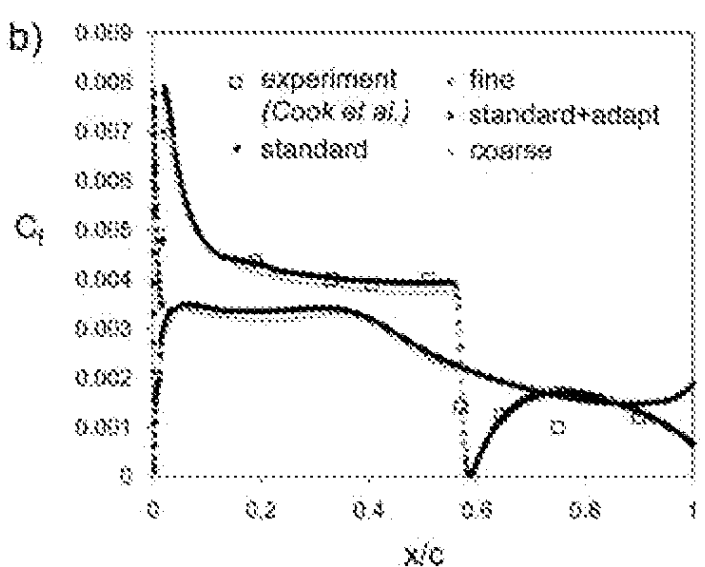

(b)

Figure 4. Fredicted pressure distributions for coarse, standard and fine meshes. 

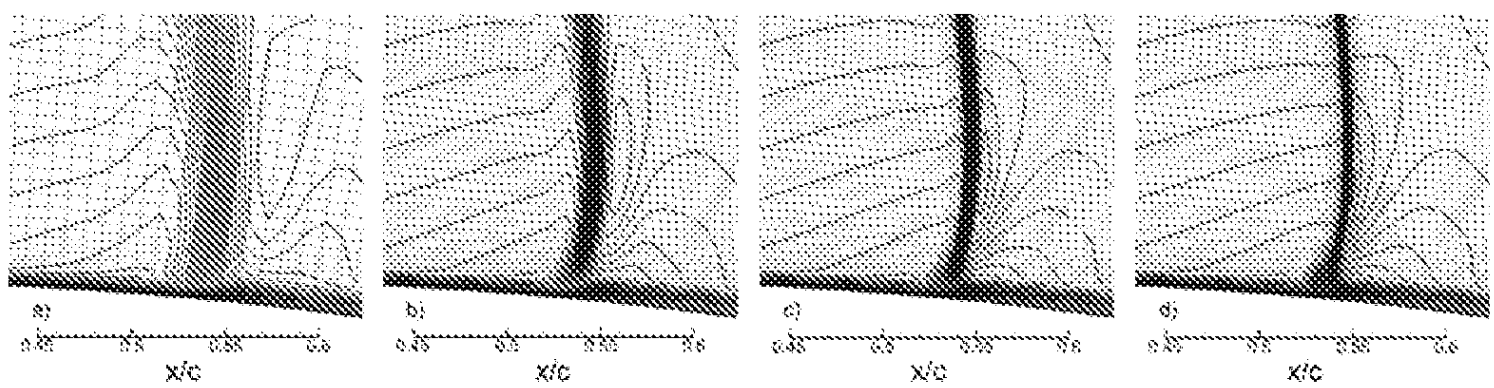

Figure 5. Resolution of density contours at the shock within the mesh for incressingly-refined node-spacing; 3) Coarse mesh, b) standard mesh, c) standard mesh first adaption, d) standard mesh with a second adaption.

around $x / c=0 \cdot 54$, and although the shock strength is shighty overestimated and the pressure recovery exaggerated in the region inmediately bebind it, agrement to the traing edge is generally good. Figure 4(a) indicates that the coarse mesh shghtly underestinates the skin friction coeficient on the apper surface over the fore half of the aerofoll, but all meskes perform very similarly at and downstream of the sbock.

A qualitative assessment of these meshes in the shock region is presented in Fig, 5 . Athough the mesh resolution does not have a marked infuence on the actual location of the shock, the smearing of the contours in the coarse and standard meshes is notable Local refmement of the mesh around the shock acheves a similar or cyen better resolution of the shock as seen with the fine mesh, albeit with only a few thousand additiond cells, and thus was adopted as the preferred metbod in order to better capture the more complicated shock structures, including reflections, seen in the ground effect study.

Comparisons to the exporimental lift and drag values are presented in Table 1 . The experimental results do not incorporate a measure of error, but nevertheless the simulations provide a good matoh, with only the coarse nesh falng to acheve adequate drag predictions. There is essentially hithe to choose beween the other meshes, and it is noted that while lin is within 1 to $2 \%$ of the experimentally-obtaned value, drag is over-predicted in all cases and thus that feature is independent of the mesh density.

Table 1

Predicted lift $\{a\}$ and drag (b) coefficients for difierent meshes

$\begin{array}{cccccc} & \text { Expeximent } & \text { coarse } & \text { standard } & \text { fine strudarditadspt } \\ C_{L} & 0.803 & 0.791 & 0.789 & 0.789 & 0.789 \\ C_{b} & 0.0168 & 0.0142 & 0.0177 & 0.0177 & 0.0177\end{array}$

\subsection{Turbshence modelling}

The Spalat Almamas (SA) ${ }^{(6)}$, Realisable $k \cdot \varepsilon^{(17)}$, and $k$-a SST ${ }^{(18)}$ turbulence models were evaluated for their effectiveness in capturing the fowficld accurately. In the comparisons to experiment, transition was retained at $x / c=0.03$. However, a case was also run without transition (fully-turbulent) and, as seen in Fig. o(a), very little observable difference in shock location and strength was observed. As this diference was so minor the simulations in the main body of the ground efeet study were thus rum as fully tubulent as there was no relable free-transition comparison data for such a wide range of shock behaviour in ground effect. and imposing one or more arbitrary transition locations would bave introduced an additional infuential variable. 


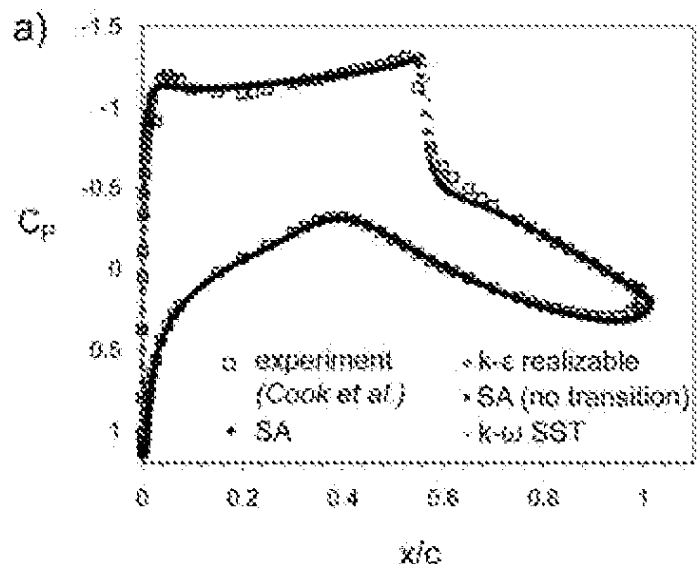

(a)

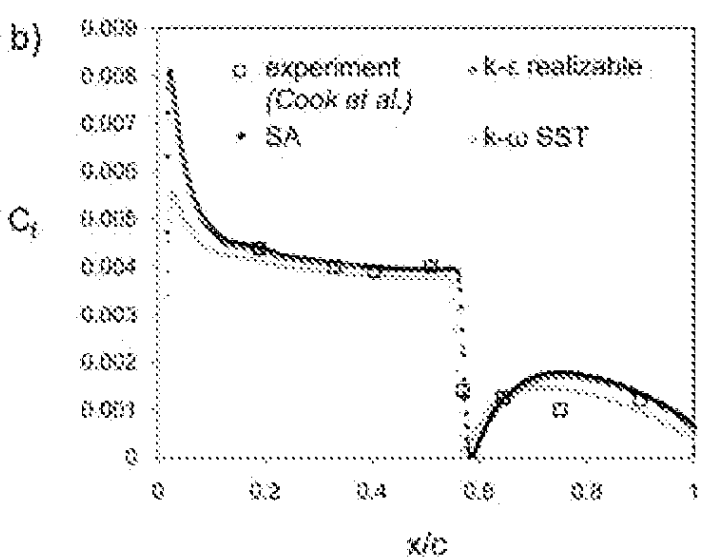

(b)

Figure 6. (3) Predicted pressure coeficients for two turbulence models with and without forced transition at 0.030 , and (b) predicted skin friction coefficients with forced transition (upper surface only).

The pressure distributions for all models in Fig. 6(a) show relatively minor differences between the predictions of the urbulence nodels, with the SA and Realisable models proving to be narginally closer to the experimental readings in the region of the shock. The SA model is also closest in reproducing the experimental lift coefficient, as shown in Table 2, albough drag is still somewhat over-predicted. The case involving fixed transition actually features increased drag due to the shgbty ebhanced strength of the shock wave and the small increase to boundary layer thickness. The results indicate that the model will most accurately reproduce the experment wh the Spalat-Allmans model when the ransition is considered, but a tully-turbulent assumption is generally a very good approximation of the fow. This is particularly true for the parametric stady which follows, where it is not necessary to consider transition as a variable in order to compare the results. Comparisons to skin-friction cocficients in the vicinity of the shock indicate that the SA turbulence model chosen bas been shown to adequately capture the nature of the shock/bomblary layer interaction in the validation case, as further demonstrated in literature ${ }^{(16,19)}$. It perfomance is near-identical to that of the Realisable model, with the SST prediction slighty underestimating the $C_{f}$ over the region of the mper surface forward of the shock.

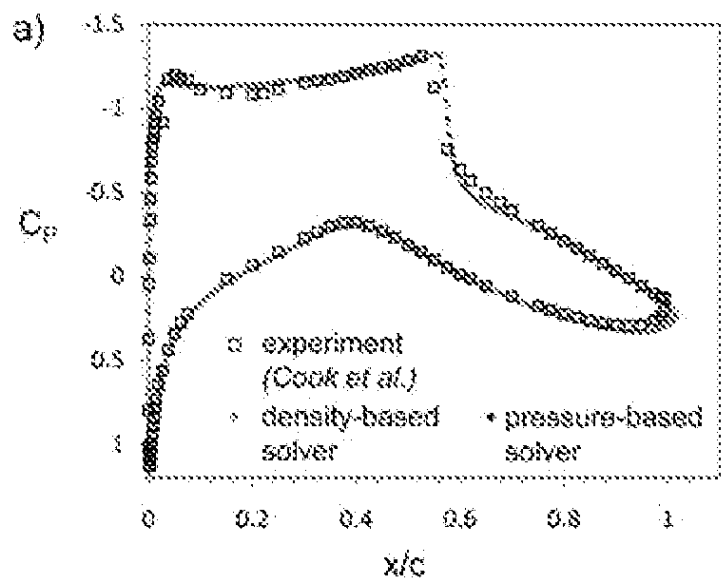

(a)

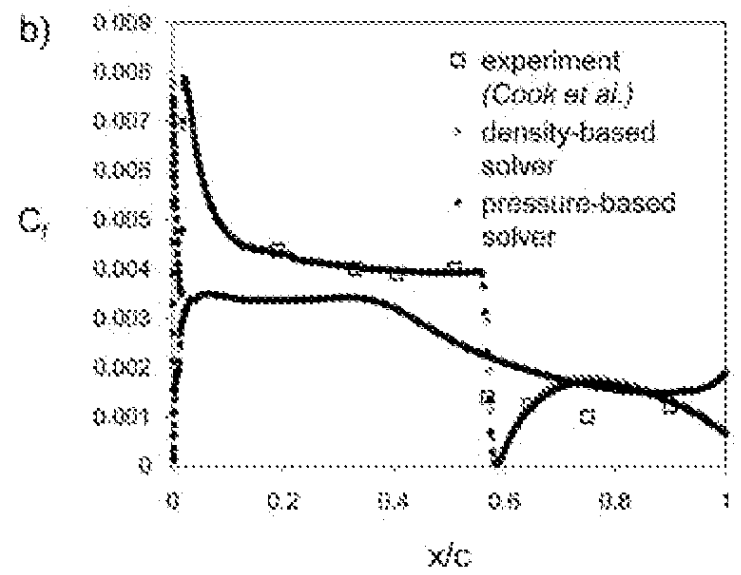

(a)

Figure 7 . Predicted pressure coefficients for the pressure-based and density-based solvers for forced iransition at 0030 , and b) predicted skin friction coeficients with forced transition. 
Retuming to the choice of solver, comparisons to the reference experiments were made for results generated by the coupled pressure-based solver already described, and the explicit density-based solver also avallable in Fluent. Figure 7 indicates an essentally negligible difference in results for predicted pressure and skin friction coefficients, however the pressure-based solver was able to achicve satisfactory convergence in tewer than halt the iterations. It also provided a nore stable flowheld in the early stages of solution, particularly as the shock wave was established, and for all these reasons was deemed to be an appropriate and preferable solver for the study described in this manuscript.

Table 2

Predicted fif (a) and drag (b) coeftcients for diferent turbulence models

\begin{tabular}{|c|c|c|c|c|c|}
\hline & Experiment & Twro. SA & Transition $S A$ & 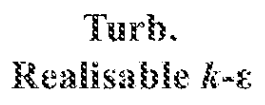 & 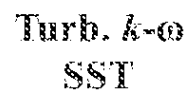 \\
\hline & 0.803 & 0.789 & 0.800 & 0.768 & 0.770 \\
\hline & 00168 & 00177 & 0.0180 & 0.0182 & 0.0163 \\
\hline
\end{tabular}

\subsection{RESULTS AND DISCUSSION}

Initially, results for AGARD 'Case 9' conditions were re-examined for various ground clearances to provide an introductory comparison of cases for increasing ground prokimity. Subsequent to this section, the full range of results for all variables is presented in tems of acrodynamic coeficients for two contexts: decreasing gromd clcarance for a fixed Mach number (analogous to redneing altitude at a controlled speed in a simation similar to that in Fig. 1), and increasing Mach number for a fixed grownd clearance (aceeleration of an arron at a fixed altivde more akin to what a wing-in-gromd effect aircraft wouk experience).

\section{3.) 'Case 9 ' with decreasing ground charance}

Here, the ground clearance is the only variable considered, in order to provide a clear indication of the effect on aerodynamic pertomance of increasing ground proximity as compared to the freeflight condition. The Reynolds number and scale remain the same as in the previous section; $6 \cdot 2 \times 10^{6}$ and a chord of $0.61 \mathrm{~m}$, respectively. As outhed in the previons section, the flowfeld was treated as fully-urbulent for all cases.

Figure 8 illustrates the way in which the pressure distribution around the aerofoil changes as the ground clarance is reduced in stages. Several points of note are immedately apparent. Most importanty, the upper surtace shock location moves progressively upstream from its freestream location, by about $25 \%$ of the chord by $h / c=0.1$. It also gradually reduces in intensity, resulting in a less severe pressure increase across the wave One of the main reasons for this behaviour is the downward movement of the stagnation point at the leading edge, which also increases the strength of the suction peak near the leading edge on the upper surtace. This increase in the effective angle of incidence draws the shock upstream, and creates a stronger adverse pressure gradient across the forward portion of the upper sarface Jeading to the earlier, weaker shock and a reduction in the region of 'rooftop' pressure distribution. The flow remains atached at the foot of the shock.

At the same time, the pressure distribution on the lower surface of the aerofoil is aftected as the air which is forced underneath is increasingly constricted by reducing ground 


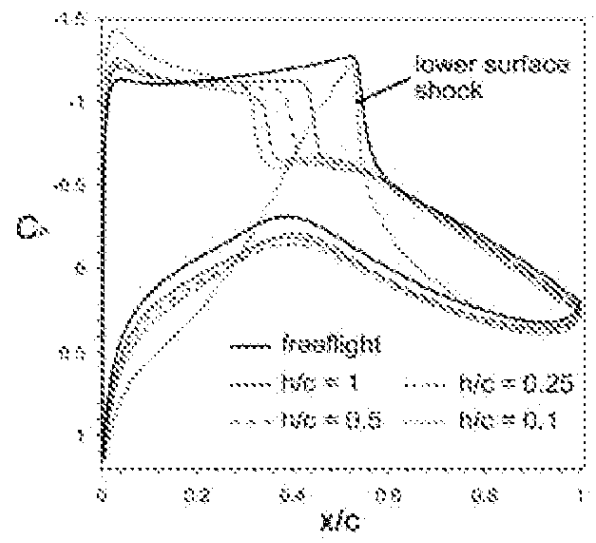

Figure 8. Pressure distribution for decreasing ground olearance at 'Case 9 ' conditons.

clenranee. As more mass is directed over the upper surface, the lower veloeity under the aerofoil causes bigher pressure in the region between the aerofoil and the grourd particnlarly near the leading edge as the stagnation point is drawn downwards, and thus the maximum pressure difference between the upper and lower surface is exaggerated with increasing proximity to the ground.

These general trends hold until the lowest ground clearanee, $h / c=0 \cdot 1$. In this case, the flow between the aerofol and the ground has accelerated to supersonic local Mach numbers, causing a strong shock wave at approximately $x / c=0.54$ as noted in Fig. 8. The lower surface Mach number local peak of approximately $M_{3}=1 \cdot 36$ occurs immediately prior to the shoek
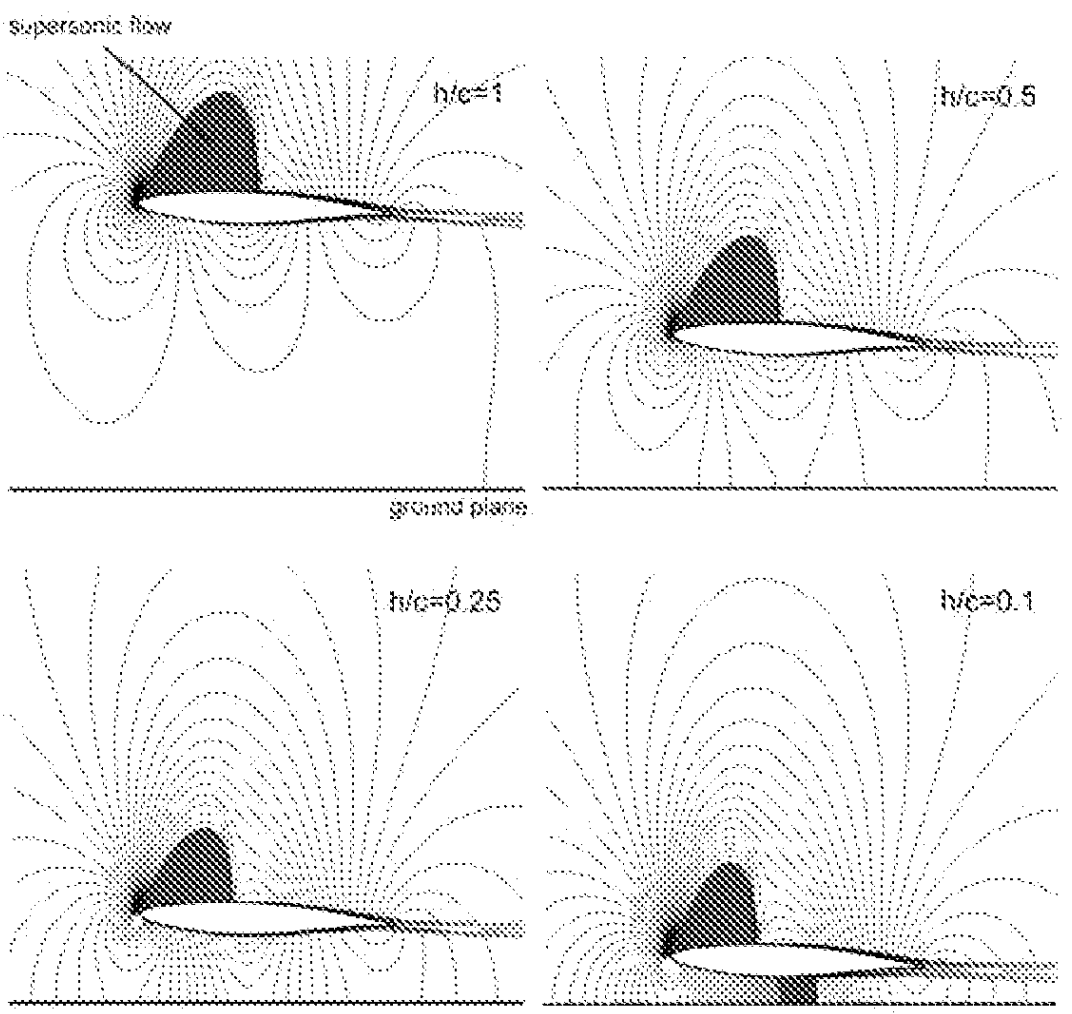

Figure 9 . Contours of density and regions of supersonic flow around the aerofoll at Case 9 conditions as ground clearance is reduced from $h / c=1$ to 0.1 . 
wave and the strength of the shock is such that it separates the fow from the surface in a small buble. As a result, the lower surface boundary layer is considebly thickened to the traing edge, and results in a broader wake boundary than at higher clearances. The forward movement and weakening of the upper shock as ground clearance is reduced, and then the emergenee of the lower shock and thicker wake, are depicted in Fig. 9.

The influence of these effects on the lit and drag coeffeients is shown in Fig. 10(a). Orag decreases with ground clearance until h/c $=0 \cdot 1$ is reached. In subsonic cases, aerofoils with atached flow tend to experience a small reduction in pressure drag as the suction over the frebody of the wing can have a component which polls the wing forwats to a small extent. The effect seen in the present cases is xelated, thowgh the large $(>25 \%)$ reduction in drag is attibutable to a much greater extent to the reduction in the strength of the shock wave, which diminishes the wave drag and lessens the thickening effect the shock has on the boundary layer (although this latter contribution to overall drag is much smaller). At $h / c=0 \cdot 1$, the drag cocfficient increases mankedy, due to the emergence of the lower surface shock and the separated flow it produces.

$C_{L}$ increases slighty from the freestream value, up $2 \%$ to ho $=0.5$ and peaking at $5 \%$ higher at $h / 0=0.25$. This is due to the increase of eftective angle of incidence caused by increasing gromb proximity, and the greater build up of higher pressure already noted between the acrofol and the ground on the foremost portion of the acrotoil, which inereases the maximam suction the section produces. The formation of the lower shock at hic $=0.1$ destroys much of this capacty to create lift, as the flow is greatly accelerated under the aerofol and produces a large amomt of low pressure prior to the shock on the af potion of the wing. This creates very strong gradients over the entixety of the chord on the lower surface. The relatively high curvature of this particular aerofoil section is a major contributor to this.

Figure 10(b) illustrates the changes to the aerofoil pitching moment (taken around the aerofoll $/ 4$ chord) while the flowfelds described above are developing. The presence of the ground serves to lessen the magnitude of the nose-down moment by between $10 \%$ and $15 \%$ at $h / c=0.5$ and 025 respectively, though this trend is not severe antil $h / c=0.1$ is reached,

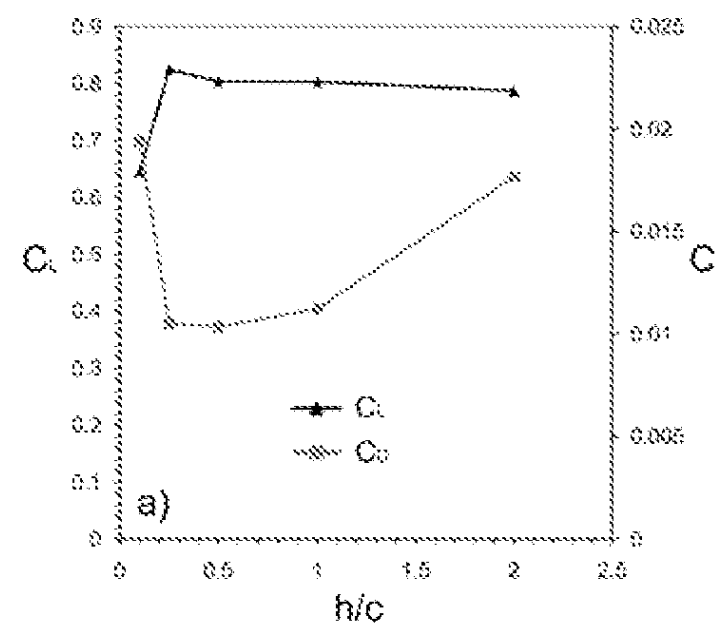

(3)

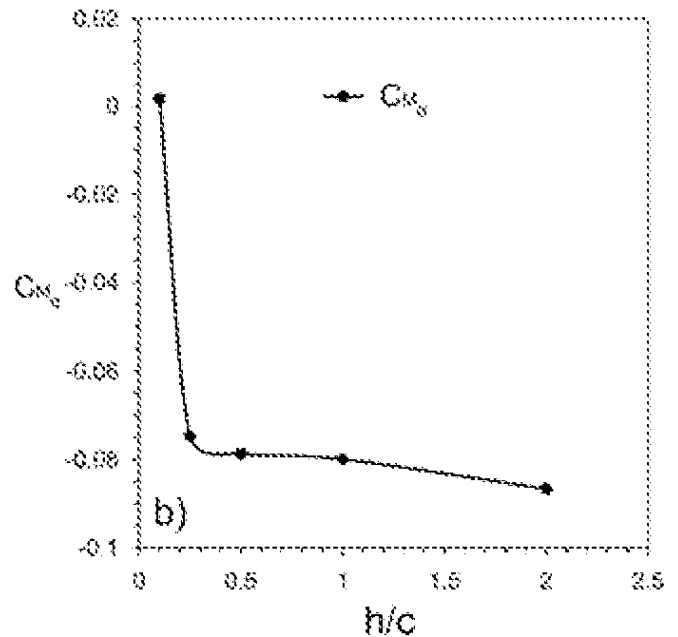

(b)

Figure 10. Lif and drag coentoients (a) and pitching moment coeficient (b) at Case 9 conditions as ground olearance is reduced from hic $=1$ to 01 
at which point the moment becomes a nose-up pitching tendency, as the lower surface shock forms behind the $3 / 4$ chord point and the strength of the upper surface suction diminishes.

Were the results for 'Case 9 ' in grownd effect to hold aeross a range of Mach numbers and angles of incidence, the aerodynamics of the aerofon in the mid-to-high subsonic regime wond be fairly predictable. However, as whll now be discussed, the thows can be very sensitive to changes in any variable. The RAE 2822 aerotoil was wed for a broad, parametrie study across several grownd clearances (freeflight (no gromd), and $h / c=1,0.5,0 \cdot 25$, and $0.1)$, Mach bumbers $(0.5,0.6,0.7,0.8,0.9)$ and abgles of incidence $\left(0^{\circ}, 2.79^{\circ}\right.$ and $\left.6^{\circ}\right)$ as outlined in Table 3 . Higher angles of incidence wond be virtually impossble to achieve in grownd effect while mantaing ground clearance at a stable croise sped, as the additional lift would pull the body away from the ground plane. Migher freestream Mach numbers than 0.9 were not examined for the two-dimensional geonetry in this case, as the inability of the flow to relax in the third dimension wonld eventualy lead to rather uncealistic detacbed bow shock waves at freestream Mach numbers far lower than that at which they could be expected to appear for any real-world body bar one with very high aspect ratio wings.

The results presented from this point onwards use an acrofoil which is sealed to be 5 times greater than that of the "Case 9 " tests, to better approximate real world hight Reynolds numbers. Thus the chord is $3.05 \mathrm{~m}$, and the chord-based Reynolds numbers for each Mach number considered are as outhed in Table 3 . The case matrix of all simulations is presented in Table 4 , and highights which cases were run as steady-state, which were run as transient but which came to a steady-state with the relaxation in time, and those which featured transient regular oscillatory shock motion. Any aerodynamic force cosficients and pressure distributions presented for the later type are the-averaged over the oscillation cycles in subsequent diagrans. For the sake of brevity a full abalysis of the transient cases is not presented here, however it is worth noting that cases featuring regular oscilatory behaviour were unambignously unsteady from early stages of the simulation, requing timesteps of the order of $0.001 \mathrm{~s}$ to produce regular behaviour satisfactorily; simulations which showed very mild unsteadiness generally stabilised to a steady state with a similar or smaller timestep, indicating that the instability was more of a numerical artefact than gemune behaviour.

Table 4 also allows the reader to see at a cursory glance which fowfields included areas of supersonic flow, and therefore in broad tems the rednction of critical Mach mumber with decreasing ground clearane for certain conditons is revealed. It is also worth noting that there is no clear pattern when it comes to the onset of unsteady shock bebaviout as indicated by the transient cases, and as such these resuls hint that the buffet boundary of the aerotol, in addition to the other nore familiar variables, may be highly sensitive to ground clearance.

Tabole

List of Mach numbers and reiated parameters

$\begin{array}{ccc}N_{\infty} & U_{\infty}\left(\mathrm{ms}^{-1}\right) & \text { Reysolds Numbere } \\ 0.5 & 170.04 & 35.52 \times 10^{6} \\ 0.6 & 20405 & 42.63 \times 10^{6} \\ 0.7 & 23805 & 49.73 \times 10^{6} \\ 0.8 & 272.06 & 56.84 \times 10^{6} \\ 0.9 & 306.07 & 63.94 \times 10^{6}\end{array}$


Tabie 4

List of simulations condwcted, detalling which cases were run as tuly transiment (marked Unsteady), which transient solutions tended to steady state (U-S) and

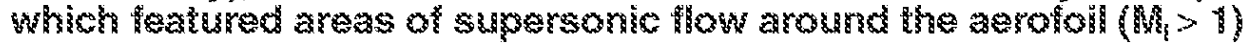

\begin{tabular}{|c|c|c|c|}
\hline hic $=\infty$ (Freetlight) & $\alpha=\beta^{\circ}$ & $\alpha=2.79^{\circ}$ & $Q=68^{\circ}$ \\
\hline$M_{z:}=0.5$ & $M_{1}<1$ & $M_{1}<1$ & $M_{1}>1$ \\
\hline 06 & $M_{1}<1$ & $M=1$ & $M_{1}>1$ \\
\hline 0.7 & $M_{1}<1$ & $\mathrm{M}_{1}>1$ & Unstendy \\
\hline 0.8 & $M_{1}>1$ & $M_{i}>1$ & $V-S$ \\
\hline 09 & $M_{1}>1$ & $M_{1}>1$ & $M_{i}>1$ \\
\hline$h / c=1$ & $a x=\left\{\beta^{\circ}\right.$ & $a=2 \cdot 790$ & $x=6^{\circ}$ \\
\hline$M_{\infty}=0.5$ & $\mathbb{M}_{1}<1$ & $M_{1}<1$ & $M_{1}>1$ \\
\hline 0.6 & $M_{1}<1$ & $\mathrm{M}_{1}>1$ & $M_{1}>1$ \\
\hline $0 \%$ & $M_{1}<1$ & $M_{1}>1$ & $U-S$ \\
\hline 0.8 & $M_{1}>1$ & $U-S$ & $U-S$ \\
\hline 09 & $M_{1}>1$ & $M=1$ & $M_{1}>1$ \\
\hline$h / c=6.5$ & $\xi=\xi^{\circ}$ & $x=2,79^{\circ}$ & $a=60^{\circ}$ \\
\hline$M_{\infty}=0.5$ & $M_{1}<1$ & $\mathrm{M}_{1}<1$ & $M_{1}>1$ \\
\hline 0.6 & $M_{1}<1$ & $M_{i}<1$ & $M_{1}>1$ \\
\hline 07 & $M_{1}<1$ & $M_{i}>1$ & $M_{1}>1$ \\
\hline 0.8 & $M_{1}>1$ & $U-S$ & $D-\$$ \\
\hline 00 & $M_{1}>1$ & $M_{1}>1$ & $M_{1}>1$ \\
\hline$h / c=3.25$ & $a=n^{\circ}$ & $x=2 \times 79$ & $a=6^{\circ}$ \\
\hline$M_{\infty}=0.5$ & $M_{1}<1$ & $M_{i}<1$ & $M_{1}>1$ \\
\hline 06 & $M_{1}<1$ & $M_{1}>1$ & $M_{1}>1$ \\
\hline 0.7 & $M_{1}>1$ & $M_{1}^{2}=1$ & $y^{2}-\$$ \\
\hline $0 \cdot 8$ & $U \ldots S$ & $V \ldots S$ & $U-S$ \\
\hline 0.9 & $M_{1}>1$ & $M_{i}>1$ & $M_{1}>1$ \\
\hline$k i c=n \cdot k$ & $q=\beta^{\circ}$ & $\{=2.790$ & $q=60^{\circ}$ \\
\hline$M_{* 2}=0.5$ & $M_{1}>1$ & $M_{i}<1$ & $U \ldots S$ \\
\hline 06 & Unsteady & $M_{1}^{2}=1$ & $M_{1}>1$ \\
\hline $0 . ?$ & $M_{1}>1$ & $M_{1}>1$ & $M_{1}>1$ \\
\hline 0.8 & Unsteady & Unsteady & $V-S$ \\
\hline 09 & $M_{1}>1$ & $M_{1}>1$ & $M_{i}>1$ \\
\hline
\end{tabular}

\subsection{Decreasing ground clearance for fixed Mach numbers}

\section{$3.2 .1279^{\circ}$ incidence}

Of the three incidences examined in this section, $2.79^{\circ}$ is most representative of an actual fight condition, as it is a lifting configuration that would be relatively low-drag, and is therefore discussed in most detail here. The angle of the section ensures that there is not as strong an 

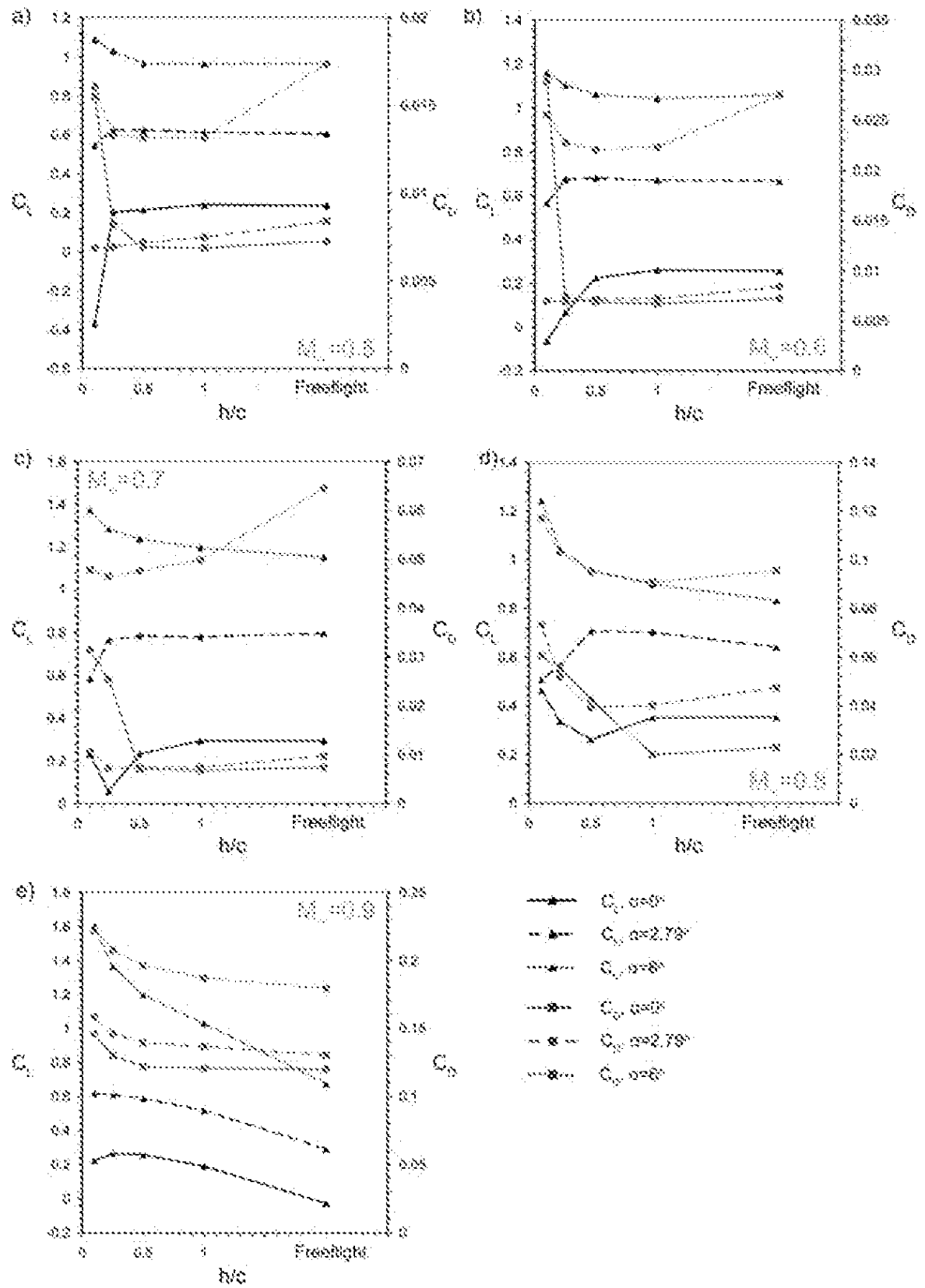

Figure 11. Lift and drag coefficients for $0^{\circ}, 2.79^{\prime \prime}$ and $6^{\circ}$, with decreasing ground clearance for (a) $M_{\alpha}=0.5$, (b) 0.6 , (c) 0.7 , (d) 0.8 and (e) 0.9 .

accleration of tow between the acrofoil and ground as at $0^{\circ}$, and there is not the strong tendency for separation on the apper sufface as at $6^{\circ}$. Acrodynamic coeffeients are presented in Fig. 11 ; aerouynamic efficiency is discussed in Section 3.3 .

$A t M_{\infty}=0.5, C_{D}$ reduces by approximately $20 \%$ from freenight to $h / c=0.1$, acompanied by a $4 \%$ increase in $C_{L}$ from freefight to $h / c=0.25$, anter which there is a marked drop at $h / c=0 \cdot 1$. The drag reduction stems from a diminisbment of the slight downwash angle of the wake from the trailing edge, as the high pressure region near the lower traing edge grows with decreasing clearance, and this also contributes to the overall lift of the section which benefits Fom a higher effective angle of incidence despite the mid changes to the wake angle The orop 
In lift at $h / c=0$ stems from a marked local acceleration of the flow arown the lower surface through the area of minimum grownd clearace, where the peak local Mach number is approxinately $13 \%$ higher than the equivalent freefight case. At higher clearances, this inereased local Mach number effect is shight.

These trends remain largely unchanged at $M_{\infty}=0.6$, but now the lift-loss at $h / c=0.1$ is more pronouneed. For cases at all the higher clearances, $C_{i}$ is proportionally higher than at $\mathrm{M}_{\infty}=0.5$, and $C_{D}$ lower, as the effect described previously are enhanced. In all cases, a small region of supersonic tow bas emorged around the upper surtace, close to the leading cdge. In freeflight, peak $M_{1}$ is 103 , and at $h / c=0 \cdot 1, M_{1}$ is 1.11

At $\mathrm{M}_{\infty}=0 \cdot 7$, the trends again remain krgely unchanged, despite all cases featuring an upper surface shock. Instead of a slight increase in lit, there is a $3 \%$ decrease fom freetight to $h / c=0.25$, though a drag reduction remains over the same range of grownd clearances. We have already seen in the previous section, for the simbar 'Case 9 ' conditions, that this is a result of the shock wave reducing in strength as it is drawn forward as the gromd is approached, with the thow having a shorter region over which to acclerate before the terminating shock. The gain in bf made from an incrsased effective angle of incidence is countered by the shortened run of acceleration prior to the shock, which raduces the low pressure the aerotol is able to generate there.

At $h / c=0.1$, there now exists a lower shock between the aerofol and ground, and a significant accompanying drag rise is observed, along with a drop in lift due to the intense pressure drop underneath the section which is the chlmination of the undersurface accleration effect whioh had been buding at this ground clearance from $M_{\infty}=0 \cdot 5$

By $M_{\infty}=0.8$, both $h / c=0.1$ and 025 fsature lower shocks, explaming the sudden increase in drag and decrease in lift at these clearances. Futher from the grond plane, the flow is now detached behind the mper shocks to the trailing edge, and results in a much stronger, thicker wake, and $s, C_{b}$ has risen an order of magnitude from the $M_{\infty}=0.7$ cases. It is clear that the closest ground clearances will affect the critical Mach muber of the secton; particularly that of the lower surface shock wave, which appoars weakly around the acrofoll in freestrean at a point close to $\mathrm{M}_{n}=0.8$, whereas at the closest grownd proximity it has been present on the wing since $M_{w}=0.6$. At clearances where the lower shock is not present, the enciency of the wing remains improved by the ground infmence.

At $\mathrm{M}_{\infty}=0.9$, extremely krge-scale shock structures axist at the traing edge. The RAE 2822 section was designed for optimal effectiveness at sub-critical Mach mumbers (design condition $M_{2}=0.66$ at $\alpha=1.06^{\circ}$ ), and so at this upper range of the Mach number scale it features very poor aerodynamic performance. Additionaly, the wo-dimensional nature of these simblations is bable to produce exaggerated shock structures that wond bo mhkely to exist in theedimensional cases up until frestream Mach numbers closer to the immediate vicinity of one. Nevertheless, the sbock structures produced, particularly at the point of ground reflecton, are worthy of inspection. In tems of the aerodynamic forces, it is sufficient to observe that the lint and brag trends are now clear and stable, as the both upper and lower shocls sit at the traing edge in both ases.

Lift coeficient increases with decreasing clearance simply because the acceleration of the upper surface continues to be enhanced by the presence of the ground, and the lower surface shock for the ground effect cases at or below $h / c=0.5$ does not sit on the aerofol itself; rather, in the supersonic nowfield, a series of weaker compression waves are generated by the traing edge contour from $x / c==096$, and subsecuently coalesee into a shock wave away from the aerofoil. Drag coefficient increases as well with decreasing ground clearance, as the strength of the shock increase and therefore so does wave drag, and the complexity of their interaction 

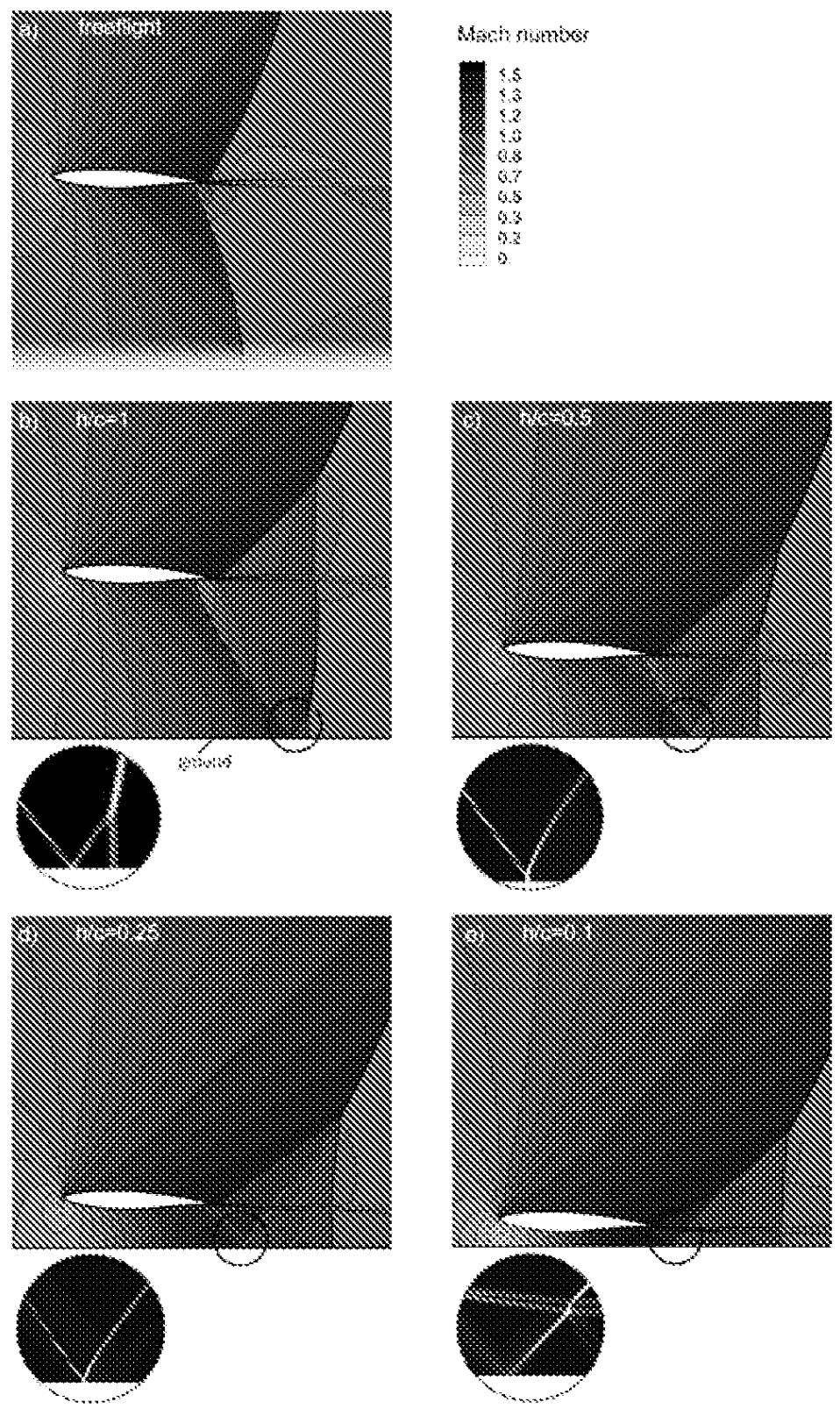

Figure 12 Contours of Mach mumber and (inset detail) numerical schlieren for cases at $M_{x}=0.9,0=2.79^{\circ}$,

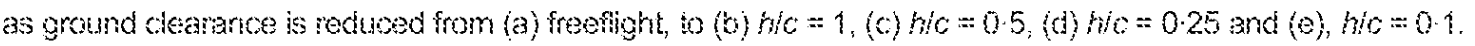

with the wake following reflection from the groubd plane in all cases serves to thicken the free shear layers traling the aerofoil.

A series of images illustrating these fearures is shown in Fig. 12 for the $\mathrm{M}_{y}=0.9$ cases, along with numerical schlicren insets detaing the nature of the ground interactions. From freefight to $h / c=1$, the peak loca Mach bumber prior to the upper shock inereases from approximately 1.6 to 1.7 , increasing the obluqe angle of the shock in the wing vicinity. This effect is exaggerated whth further proximity to the ground, as the extent of the high-Mach region increases. In all cases this oblique wave is observed to nomalise in the far ficld, many chord lengths from the aerofoll At $h / c=1$, the lower shock experiences regular reflection, which is 


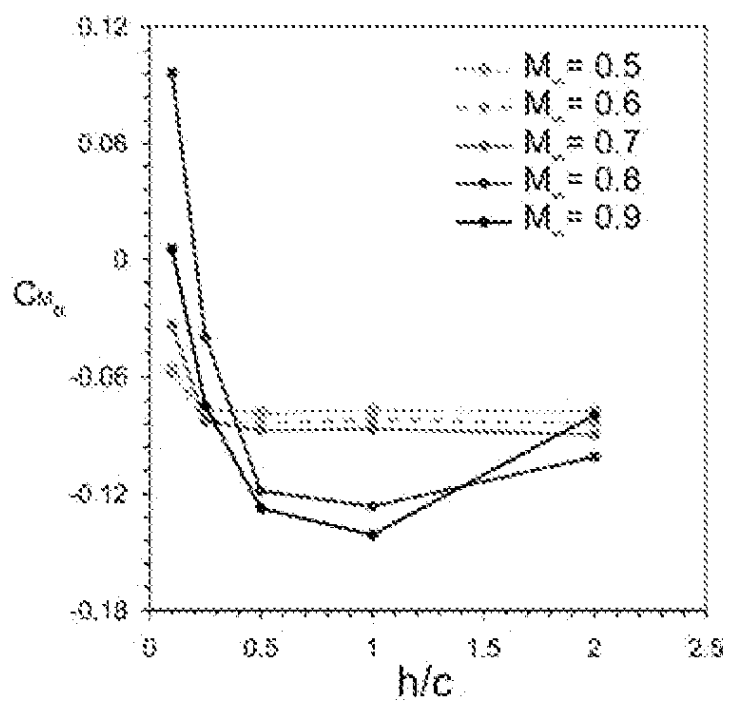

Figure 13 . Pitching moment coefficients at $\alpha=2.79^{\circ}$, as ground clearance is reduced.

followed by a normal recompression stem; these two waves join in forming a large nomal recompression approximately $0.5 c$ downstrean from the tailog edge, bringing the flowtield back to a subsonic condition. The shock structure is highly reminiseent of that generated by the F/A 18 during the bigh-speed pass captured in the photograph of Fig. 1.

At the grownd, 'lambda' shook structure, different from that seen on the wing the the validation cases, forms in the presence of the thin shear layer which has formed on the ground. This flow feature is highighted in the inset of Fig. 126), showing a triple-point forming at the mesting of the reflected incident shock and the Mach stem to the gromd surtace. The shear layer thickens behind this point.

At $h / c=0.5$, the general structure is identical, but the extent is magnified. The rotlection at the ground, which now features its own small Mach stem due to the reduction in the angle of the incident shock (and therefore takes on a mote conventional reflection structure ${ }^{20)}$, is able to pass through the wake before being joined by the strong bomal stem from the ground at close to 0.65 downstrean of the raling edge. The influence of this on the wake is to thicken it considerably, and align it with the freestrean following a mid downards deflection from the traing edge. The major triple point sits above the wake, further from the ground than the acrofon, representing a considerable evolution from the structure seen at $h / c=1$.

By $h / c=0.25$ the immodiate downwards deflection of the wake is more prominent and the reflected lower wave now passes throngh the wake and merges with the normal recompression and the upper shock at a unicue quadruple point. The lower wave itself now no longer forms at the aerotoil surtace; ratber, a series of compression waves are generated due to the curvature of the lower surface close to the traing edge. These waves coalesce into a shock at the ground piane, and therefore the refection iself is weaker -- the Mach number gradients in this region are not as pronowned as at the higher clearance.

The sane is true of the wave at $h / c=0.1$, and the peak local Mach number in the flow field now occurs at the ground plane immediately pror to the shock retlection. The upper wave now merges with the reflection of the lower wave prior to the nomal recompression to subsonic conditions, which ocurs $0.8(0)$ downstream of the trailing edge. The refected lower wave straightens the wake to parallel with the freetream, but the bumerical schieren in the inset of Fig. 11(e) indicates that a weak reflection of the wave from the shear hyer also exists, and the 


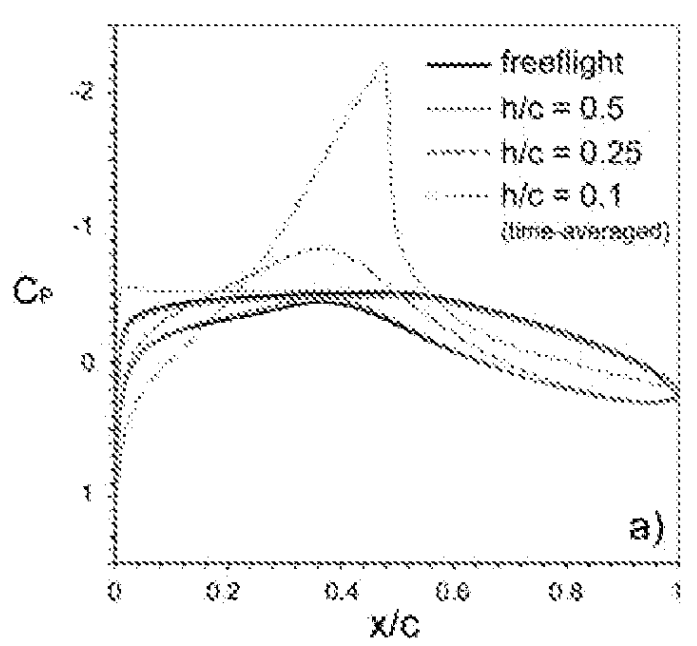

(a)

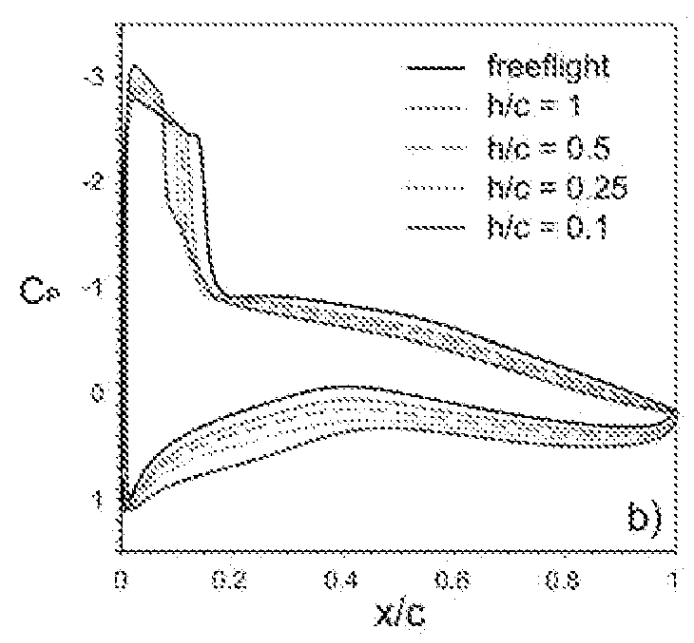

(b)

Figure 14. Pressure distributions at $M_{\infty}=0.6$ for $(a) \alpha=0^{\circ}$ and $(b) \alpha=6^{\circ}$ as ground clearance is reduced.

wave itself bends signifoanty in passing through the shear layers. However, its angle in exing this region is essentaly unchanged from that prior to the interaction.

Figre 13 presents a plot of pitching moment coefficient, taken aromd the $1 / 4$ chord mark, for $\alpha=2.79^{\circ}$, as gromd clearance is reduced and for the five frestrean Mach numbers investigated. At $M_{c}=0.5$ through 0.7 , the nose-down moment is farly constant with decroasing clearance, until $h / c=0.1$ is reached, at which point the moment becomes notably less negative due to the increase in low pressure forming between the aerofoil and the ground. This reaches its peak behind the $1 / 4$ chord and therefore contributes a nose-up (positive) component. At $M=0.8$, the negative moment increases in magnitude from freeflight to h/c $=1$, after which it becones considerably less negative with furtber reduction in ground clearance, eventually producing an overall nose-xp moment at $h / c=01$, coinciding with the point where the lift coefficient was seen to drop away in Fig. 11 .

\subsection{0 incidence}

Although not typical of a light incidence except in momentary pitching, the $0^{\circ}$ cases provide the most exaggerated ground effects due to the lower sutace producing a relatively stronger ventwi effect between the aerofoil and the ground.

Returning to Figure $11(a)$, for $M_{\alpha}=0 \cdot 5$, the lift coefwont is seen 10 decrese shgbty as ground clearance is reduced. This is a direct consequence of the increasing acceleration of the fow between the aerofol and ground, which is more exaggerated at this incidence than at $2.79^{\circ}$, and means that the stagnation point is drawn upwards by a small margin. At $h / c=0 \cdot 1$, the lif coefteicnt reverses sign, and the section produces a negative $C_{L}$ of $-3 \cdot 39$, or roughy $-200 \%$ of the lift produced at $h / c=0.25$. The drag coeffient initially reduces by a small margin $(l$ $2 \%$ ) to hic $=0.5$, after which it increases sharply with further proxinity to the ground. At h/e $=0.25$ this is simply a function of the accelerated how around the wing causing a slighty thicker wake, but at $h / c=0 \cdot 1$ a shock wave has fomed on the lower surface. There is no significant separation at the foot of the shock but the wake is markedly thicker as a result of the shock/boundary layer interacion.

For $M_{n}=06$, in $F$ ig. $11(b)$, the trends are almost identical apart from that the marked dropoff in hif and mild increase in drag at $h / c=0.25$ (where hit remains positive in sign), as well 
as $h / c=b \cdot 1$ where the lower surace shock is present (again producing negative $\mathrm{hifh}$. At $h / c=$ 0.25 this new trend is cansed by the increased acceletron of the flow under the wing, where the peak local Mach number now 0.85 , as opposed to a peak of $M_{1}=0.73$ on the lower surface in the frectlight case. The $h / c=0 \cdot 1$ lower surtace shock, which has begun oscillating, has now triggered significan periodic boundary layer separation from the shock foot to the tralling edge, and is the cause of the exponential rise in $C_{0}$, close to $100 \%$ bigher than at the same clearance at $\mathrm{M}_{x}=0.5$.

Altbough other cases feature shock oscillation (noted in Table 4), this case was the only one to prodnce mild buffet fow specifically with the lower shock, and therefore has been singled out as a briet example. The shock movement was limited to a $003 \mathrm{c}$ portion of the acrofoll, with a low oscillation frequency of $16 \mathrm{~Hz}$. The shock foot periodically separated the boundary layer to the trailing edge.

The evolution of the flow wh decreasing ground clearance to produce this flowfeld is highlighted in Fig. 14. Aerotol pressure distributions show the relatively mild ground infuence at hic $=0.5$, where the distribution is close to that of the freeflight case. At h/c $=0.25$, the acceleration of flow in the acrofol/ground channel lowers the pressure there, while the apper surface distribution remains similar. Then, at $h / c=0 \cdot 1$, the shock wave forms, causing a large low pressure spike on the lower sutace. With the flow so restricted underneath the aerofon, the air directed over the upper surface produces a greater suction peak close to the leading edge, though this is more than ofset by the negative hit produced by the suction region prior to the shock.

At $M_{s}=07$, a shock has now fomed on the lower surface at $h / c=0.25$ and at $h / c=0.1$. The effective choking of the flow between the aerofoll and grownd has forced sufficient air over the npper surface to result in neat-sonio conditions there. The lower surface shock was not oscillating, indicating that the increased Mach number lies on the far side of the buffet boundary produced by this wave. The drag rise now begins at $h / c=0.25$, though no significant separation exists from that shock.

For $M_{\infty}=0.8$, in Fig 11 (d), the marked drag rise is now present at $h / c=0.5$ too; the flowflold incorporates both an upper and lower surface shock system. At $h / c=0 \cdot 1$, the flowtield is signiticantly tansient once more, as the apper surface sbock is now oschllating, with the periodic separation stuctures at the trabing edge triggerng a nild novenent in the lower sbock as well. $C_{L}$ initially drops as ground clearance is rednced from $h / c=1$ to 0.5 , but then increases despite the presence of the sbocks. The fow is being forced over the upper surace to an extent that the low pressure regon there is much extended with decreasing clearance, thongh it does result in a stronger shock sitting further back on the aerofoll.

At $M_{2}=0.0$, extremely large-seale shock structures exist at the traing edge as in the previous section, although they are not suticiently different enough from the $2 \cdot 79^{\circ}$ cases, in terms of general characteristics, to warant a detaled description here.

\section{$3.38^{\circ}$ incidence}

Athough the incidence here is high enough to promote large-scale separation on the mpper surface, the flow between the aerofoll and gromd is closer to the 'ram' effect that can be acheved at lower incidence for a more fat-bottomed aerofol section ${ }^{3}$, as the profle is farly parallel with the ground from the pont of minimum gromd clearance to the trabing edge. In this scenario, the region under the aerofon is almost exchisively a high pressure zone, and features relatively tintle local acceleration due to curvature. 

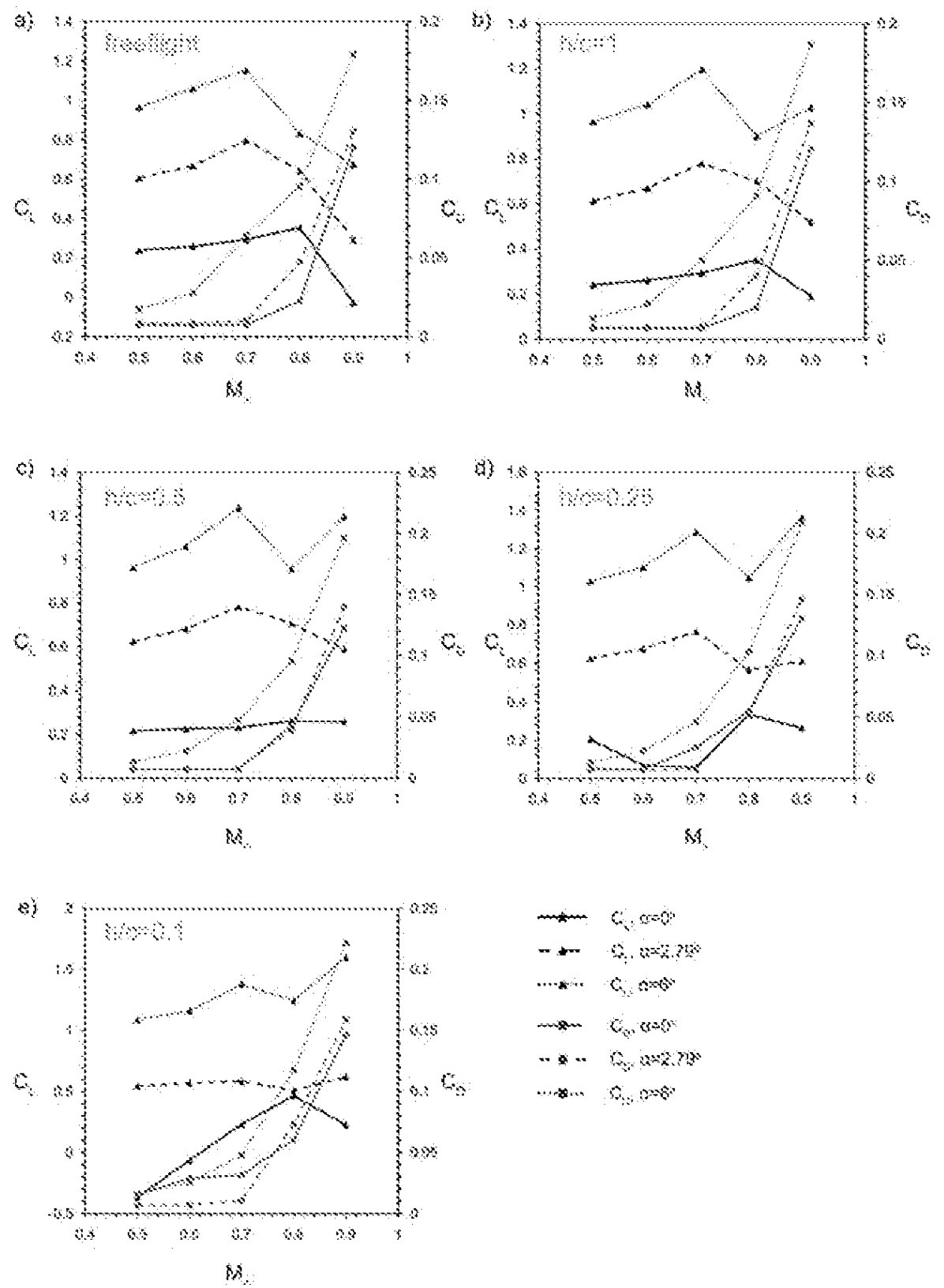

Figure 15. Lift and drag coefficients for $0^{\circ}, 279^{\circ}$ and $6^{\circ}$, whth decreasing ground clearance for (a) $M_{2}=0.5$, (b) 0.6 , (c) 0.7 , (d) 08 and (e) 0.9 .

In the absence of lower surace shock waves wp until $M_{w}=0 \cdot 9$, most of the observed changes to lift and drag, refering back to Fig. 10, are due to the infuence of the ground on the mpper surface sbock. At $M_{\infty}=0.5$ and $0.6, C_{b}$ only shows distinct inprovenent at $h / c=0.25$ and $0 \cdot 1$. Above this clearance, the 'ram' effect is not as strong. Frior to $h / c=01$, the drag reduces by almost $24 \%$ in ground effect as compared to the freethight case, as the shock wave moves even further towards the leading edge, and the thickness of the upper shear layer leaving the aerofol at the tralling edge is reduced as a result. The downwash angle of the wake is also lessened ( $1-2^{\circ}$ in the immediate vicinity of the trailing edge). At the lowest clearance, lift and drag increase from their levels further from the ground. The drag increase is due to the fact that altbongh the shock is even further forward on the profle as a result of the continued increase to cffective angle 


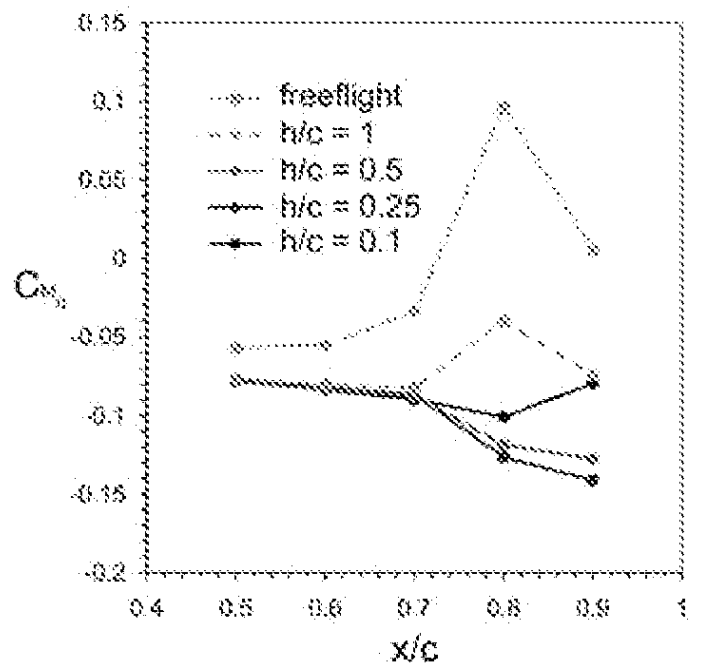

Figure 16. Piching momen coefficients at $\alpha=2 \cdot 79^{\circ}$, 3s Mach number increases.

of incidence, the flow is now significantly separated at the foot of the shock and therefore the boundary layer following reattachment downstream remains thicker and increases the strength of the wake as a result. Pressure coefficients with decreasing clearance for $M_{y 2}=06$ are shown in Fig. 14(b) to illustrate these effects.

These trends contme to hold $a \mathrm{at} \mathrm{M}_{x}=0 \cdot 7$, though the drag now increases across the range as separation bubbles at the shock foot are present in all the cases. The influence of the ground to this point appears to be to invoke the onset and sabsequent magnification of separation by virtue of continued increase in the effective angle of incidence. However, the ablity of the wing to produce ever-increasing levels of lift as clearance is reduced for a fixed Mach number is not affected. At M $=0.8$, with every case producing large areas of separated flow to the traing edge, the 'ram' effect on the lower surface still results in increasing efficiency as the aerotoil is placed closer to the ground.

At $\mathrm{M}_{\infty} 09$, lift and drag both increase as ground clearance is reduced. he freeflight, the upper surface shock sits at the traling edge, forming a lambda-foot with the upper shear layer behind the trailing edge, while a strong shock exists on the lower surface past the point of maximum thickness. After this compression, the lower surace flow accelerates to supersonic again, resulting in a scond, much smaller, shock coincident with the stem of the upper shock.

At $h / c=1$, the initial lower-surface shock has reduced greatly in magnitude, and the secondary region of supersonic flow is now much expanded, extending to the gromd plane and foming a large-scale curved recompression shock. This stmeture does not cbange characteristics as clearance is further reduced, though the peak local Mach muber prior to the apper shock increases and the fral recompression behind the aerofoil exist increasingly downstrean of the trailing edge as was seen for the $2.79^{\circ}$ case. The elmination of the initial lower surface sbock seen at higher clearances greatly increases the ability of the wing to produce lift.

\section{4 increasing Mach numbers for fixed ground clearances}

For the three incidences exammed, data is reconstructed in Fig. 15 for fixed angles of incidence and grownd clearances as Mach number increases. This is bricty examined here as it is approximately representative of attempting fight at a constant attinde and altude duning long-term 
accelaration, albeit at a slow enough rate so that the flow is stady-state at any given time. This provides a diferent way of interpreting the results. It ignores the intrinsic short tem efect of sudden acceleration, which would aler the results were this a truly time-dependent increase in frestream Mach number. Freethight results are included for comparison.

\section{$3.4 .30^{\circ}$ incidence}

In freeflight, lift and drag coefficients increase with Mach number, until at $\mathrm{M}_{2}=0.9$ lift production drops off. At $h / c=0 \cdot 5$, this drop is elminated and hecofficient remains largely constant through the Mach number range, though the drag increases at a greater magnitude. This clearance produces the most stable trends; at $h / c=0.25, C_{D}$ at first decreases from $M$ 0.5 to 0.6 , then increases to $M_{\infty} 0.8$, then decreases again to $M_{\infty} 0.9$, due to the influence of the fomation of the lower surface shock. The transonie drag rise begins between $M_{\infty} 0.6$ and $\mathrm{M}_{0} 0.7$ as a result, rather than between $\mathrm{M}_{\alpha} 0.7$ and $\mathrm{M}_{\alpha} 0.8$ at the higher clearances. $\mathrm{At} h / \mathrm{c}=$ 01 , as we have already seen, the wing produces negative lift mint $M_{\infty} 0.7$, and as the lower surface shock bas already fomed prior to $M 0.5$, the transonic drag rise has already established itself.

\section{$3.4 .22 .79^{\circ}$ incidence}

With increased incidence, trends for lift and drag with increasing Mach number remain similar from freefight to $\mathrm{h} / \mathrm{c}=0.5$, with the flowhelds at $\mathrm{M}_{\alpha} 0.7$ representing a peak in the lift coefficient after which it drops of with the additional acelention under the aerofol to the point at which the lower shock forns. Drag rises predictably and asymptotically with Mach number for these cases and those ar lower gromind clearances as well. At $h / c=0.25$ and $0 \cdot 1, C_{l}$ still peaks at $M_{c o} 0 \%$, then drops, but maks a partial recovery at $M_{o j} 0$.

Pitching moment coefficient trends for this incidence are presented in Fig. 16, and show a clear distinction between the clearances from freethoht to $h / c=0.5$, and those at $h / c=0.25$ and 01 . A spike in the $\mathrm{CM}$, at $\mathrm{M}_{0} 0.8$ at these latter clearances is due to the marked shift forwards of the peak high pressure region, which now dominates the lowor region close to the leading odge, rather than at the point of mimimum clearance or the trailing edge where it is produced more

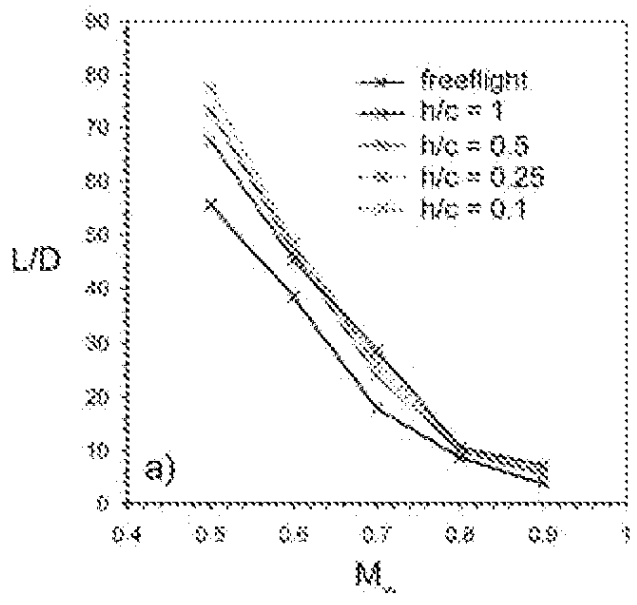

(a)

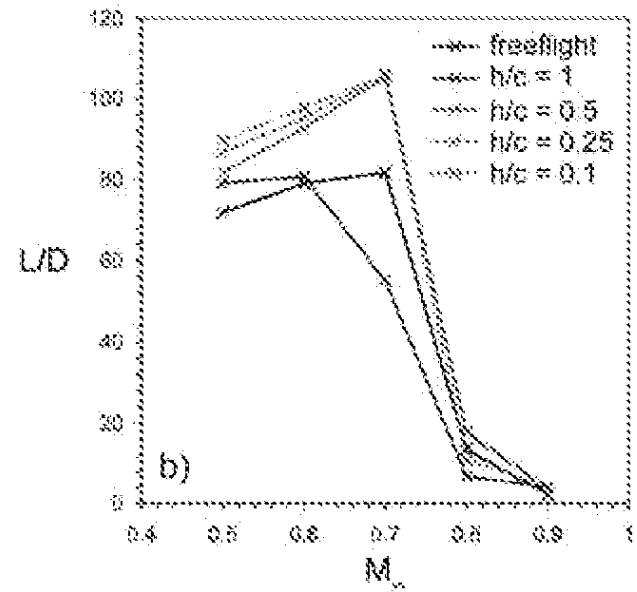

(b)

Figure 17. Aerodynamic efficiency, 40 , at (a) $279^{\circ}$ and (b) $6^{\circ}$ for different ground clearances as Maon number is increased. 
naturally around the aerofol without the constriction of the ground, at higher clearances. Clearly, the trim of an aircraft at low clearances accelerating or decelerating through the Mach number range would be comtimously changing. This wouk ocour abruptly in the case of lower shock fomation, and wond imply a necessity for rapid-response pitch correction to maintain attude. Altematively, any sudden change to altinde over the small gromd clearanee range would have significant effects fot stability at a constant hoht Mach number.

The aerodynamic efficiency of the aerofoil at the varions gromd clearances with increasing Mach number is shown in Fig. 17. The lower-surface-shock dominates the flowfeld at h/c = 0.1 at $M_{\infty} 3.6$ onwards, with the immediate result being that it is considerably less effecient to fy at this gromd clearance than in freenght. The clearances of $h / c=0.25$ represents the best efficiency gains mati $M_{m} 0.8$, at which point the aerofoil at all clearances features a shock on the lower surface and thus hf drops of as drag increases. The peak efficiency for all clearances bat $h / c=0 \cdot 1$ comes at $M, 07$, beyon whoh large-sede sbock-induced separation destroys the advantages of tying in gromb effect.

\section{4 .36 incidence}

At the maximum incidenee, the lift and drag behaviows are similar to those at $279^{\circ}$, with a peak in $C_{L}$ occurring at $M_{\infty} 0.7$ for all cases fom freefight to $h / c=0.5$. In freeflight the drop off in $C_{2}$ is continuous thereafter, whereas at the bigher ground clearances a partat recovery is made at $M_{\infty} 0.9$ as the 'ram' effer under the acrofol continues and extensive separation on the apper surface of the wing is bo longer possible with the shock waves now sitting at the trailing edge. The disappearanee of the lower suface shock over these dcaranees serves to ab greatly in the recovery of lif. At h/c $=0.1$, the drop in $h \mathrm{~h}$ at $\mathrm{M}_{2} 0.8$ is mild, such is the increase to effective angle of incidence at this clearance, and thus at this clearance the wing remains more efficient through the Mach range than in freethght as shown in Fig, 16, alhough the large-scale separation it produces means that is is Bever more than a few pereent more efficient than the lower-drag cases at higher ground cleartnces. The figure also highights a clear trend towards decreasing efficiency with increasing Mach number (in grownd effect as in freeflight), with the shock-separation induced drag the prime contributor to this.

\subsection{CONCLUSIONS}

An RAE 2822 aerofoil section at Reynolds numbers approximating fight conditions was examined for mbitiple grownd clearances (frettight (no ground), and $h / c=1,0.5,025$, and $0 \cdot 1$ ), Mach numbers $(0.5,0 \cdot 6,0 \cdot 7,0 \cdot 8,0.9)$ and angles of incidence $\left(0^{\circ}, 2 \cdot 79^{\circ}\right.$ and $\left.6^{\circ}\right)$.

In general, the ground effect mechanisms that result in increased lift and often cohanced efficiency at much lower Mach numbers also hold at high-subsonic Mach numbers. High pressure increases mdemeath the aefofol as more mass fow is directed over the upper surface, leading to an increase in effective angle of incidence. This is rarely the case at very low clearances (h/c $=0.1$ ), where the local curvature at the leading edge on the lower surface encourages the flow to acelerate under the section to ereate enough low presure over the midde portion of the aerofoil to have a strong destructive effect on hift.

The onset of shock waves in the flowfield bas a disuptive effect on perfomance, particularly at the lowest clearances, where the early formation of a shock wave beween the acrofon and ground can load to a sudden drop in the production of lift and an accompanying early trassonic drag rise for the section. It can also lead to the development of unsteady shock oscillations on 
the lower surface, and has a considerable effect on the pitching moment of the section, lending it a nose-np noment at low clearances where it would nomally have a nose-down moment at higher clearances and in freeflight.

While an aerofoil could be optimised to delay or mitigate many of the andesiable effects described, it remains clear that sustained hight close to the ground at ransonic Mach mumbers would be particulatly diffoult without an advanced control system to accomnt for very tapid changes to lit, drag and pitching moment caused by relatively small changes to ground clearance, incidence or Mach number For instance, if flying olose to the critical Mach umber for the lower surtace at $h / c=0 \cdot 1$, even a sudden strong headwind gust could result in the abrupt formation of a shock wave between the aerofol and gromb causing a precipitons loss in lif and therefore altitude.

The results indicate that whout furher research into approprate aerofoil shapes and longitudinal control, a caft specifically designed to fly in grond effect at high subsonic Macb rumbers is not a feasble prospect, and thus an "upper linit' to the crusing Mach number of snch a craft wond apply. The aerodynamic efficiency of the section at different ground clearances for increasing Mach mmber indicated that the onset of supersonic flow on the lower surface, achieved as early as $M_{\infty} 0 \cdot 5$ at $h / c=0 \cdot 1$, means that thight in close ground proximity is no longer more efficient than frectlight. At the higher ckarances, a peak in $L / D$ occars at $M_{\infty} 0.7$, beyond which there is little gain to be made by tying in ground effect, as incroased separation and lower surface suction cancel out any enhanced effective angle of incidence.

\section{ACKNOWLEDGEMENTS}

The abthors gatefully acknowledge the support of The Royal Acromatical Society: collaboration between the Unversicy of New South Wales and the US Naval Acadeny was made possble thanks to the RAeS though a Centemial CAARC Award to the primary axthot.

\section{REFERENCES}

1. BARBER TY, LEONARD E and ARCHER R. D. Calses for discrepancies in ground effect analyses, Alemaut $J, 2002,106,(1066)$, pp 653-657.

2. AHMED, M.R. and SHARMA, S.D. An investigation on the aerodynamios of a symmetrical arfol in ground efiect, Experimental Thermal and Fidd Science, 2005, 29, pp $633-647$.

3. RozmesrverskX, K.Y. Aerodynamics of a Lifing Systern in Extreme Ground Effect (text), Ist ed., Springer-Varlag, New York, USA, 2000.

4. Powel, J., Marse, G., Maniagua, J. And Ratrer, J. Maglev Launch and the Next Race to Space, DEE Aerospace Conference Procedings, 2008 , Big Sky, USA.

5. Scherz, JA Aerodynamics of High Speed Trains, Anmal Review of Flud Mechanics, 2001, 33, p) 371.414.

6. Rozmbervensky, K.V. Wing-in-ground effect vehicles, Frogress in Aerospace Sciences, 2006, 42, (3), pp $211-283$

7. MASKaLK, A.I and RozmberveksK, K. V. A View of the Present State of Research in Aeroand Hydrodynamies of Ekramoplans, RTO AYT Symposinn on Flud Dynamics Problems of Vebicles Operating near or in the Air-Sea Bnterace, Amsterdam, The Netherlands, $5-8$ October 1998.

8. DRAGos, $L$. Numerical solutions of the equation for a thin airfoil in ground efrect, 1950, ALA $d$, 28, (12), pp $2132-2134$

9. DRACOS, $L$. and DNT, A. A direct boundary integral equations method to subsonic flow with circulation past thin airoils in ground effect. Comput Methods Appl. Mech Eng, 1995, 121, pp $163-176$ 
10. COOK, PM. MCDONALD, M.A. and FrMn, MCP. Aerofoil RAE 2822-Pressure Distriburions, and Boundary Gayer and Wake Measurements. Experimental Data Base for Computer Program Assessment, 1979, AGARO Report AR 138.

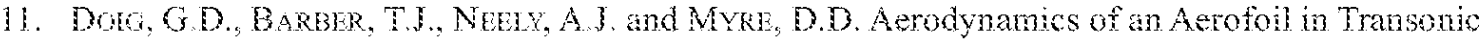
Ground Gffect: Methods for Blowdown wind-twmel Scale Testing. Submited to the Aemontical Jounal, November 2010, revised May 2010

12. Fluent User Gaide, 2006, FLUENT Inc., Lebanon, NH.

13. Sunter AND, W. The viscosity of gases and molecular force, Philosophical Magkzine, 1893, 5, (36), pp $507-531$

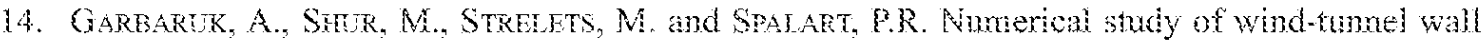
effects on transonic airfoil flow, ALAAJ, 2003, 41, (6), pp 1046-1054.

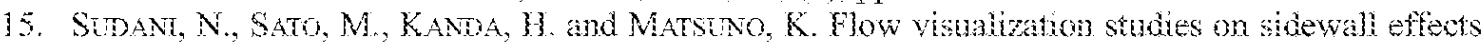
in two-dimensional transonic airoil testing, $I$ Aircr, 1994, 31, (6), pp $1233-1239$.

16. SPA ART, P. and AUMARAS, S. A one-equaton turbulence model for aerodynamic llows, 1992, A AA Paper 92-0439.

17. SHH, T.H. LJO, W.W., SHABEI, A., YANG, Z. and ZH, J. A new $k$-s eddy-viscosity model for high Reynolds number turbulent flows - model development and validation, 1995, Computers f Finds, $24,(3)$, po $227-238$

18. MEATR, FR. TWo-equation eddy-viscosity turbulence models for engineering applications, $A T A S$, $1994,32,8$, pp $269-289$

19. RUMSEX, C... and VATSA, VR. A comparison of the predictive capabihties of several turbulence models using upwind and centraldiference computer codes, 1993, Proc. 3 lst ALA Aerospace Sciences Meeting, Reno, USA pP $1-16$

20. SZWABA, K., DOERFFE, P., NAME, K. and SZUL, O. Flow stucture in the region of three showk wave interaction, Aeropnce Science and Technology, 2004, 8,6$)$, pp 499-508. 